\title{
[editorial]
}

\section{Osteoartritis de la primera articulación carpometacarpiana}

\section{Oscar Luis Rillo}

Jefe de Sección Reumatología, Hospital General de Agudos "Dr. Ignacio Pirovano". Ciudad Autónoma de Buenos Aires.

La osteoartritis (OA) de la articulación carpometacarpiana del pulgar (rizartrosis del pulgar u OA de la articulación trapeciometacarpiana) es una condición particularmente prevalente en la mujer postmenopaúsica, llegando en esos casos hasta el $36 \% \%^{1,2}$.

Generalmente bilateral, puede ocasionar dolor, rigidez, debilidad y alteración funcional de la prensión digital (pinza digital), lo que restringe la capacidad para realizar actividades de la vida diaria ${ }^{3}$.

Es el segundo sitio más común de enfermedad degenerativa en la mano después de la OA de la articulación interfalángica distal. Puede ocurrir en forma espontánea, probablemente con una predisposición genética (idiopática). Entre sus factores de riesgo se hallan el sexo femenino (mujer/hombre: 6/1), hiperlaxitud ligamentaria, mayor edad, uso repetitivo de la articulación, trauma previo (afección unilateral) o enfermedad articular inflamatoria (por ej., artritis reumatoidea) (-7. $^{4}$.

Se ha comunicado que la prevalencia radiológica en hombres y mujeres mayores de 75 años es del $25 \%$ y $40 \%$ respectivamente, aunque no todos son sintomáticos ${ }^{5}$. En el examen clínico la articulación puede hallarse "laxa o rígida". La cuadratura articular confiere la denominada "mano cuadrada" con aducción fija de la base del pulgar y que resulta en los estadios tardíos en una hiperextensión secundaria de la articulación metacarpofalángica.

En el diagnóstico son de gran ayuda el examen radiológico (vistas anteroposterior, lateral y oblicuas del pulgar) y maniobras provocativas de dolor como el "test del crujido". Las lesiones características son el estrechamiento del espacio articular, osteofitos, esclerosis subcondral, quistes y subluxación, y podrá determinarse los grados de lesión radiológica por medio de la escala de Kellgren y Lawrence ${ }^{8}$. Recientemente se ha comunicado la presencia de lesiones erosivas (OA erosiva) en la primer articulación carpometacarpiana, con una prevalencia de 2,2\% (IC 95\% 1,4-3,3). Solamente el 0,5\% (IC $95 \%$ 0,2-1,2) tuvo enfermedad erosiva afectando las in- terfalángicas y la primer articulación carpometacarpiana en forma combinada?.

En una etapa tardía, las radiografías pueden mostrar cambios degenerativos en la articulación trapecioescafoidea y una deformidad en "zigzag". La presencia de sintomatología, crepitación, inestabilidad articular, hipo o atrofia de los músculos de la eminencia tenar y los mencionados hallazgos radiológicos permiten clasificar los pacientes en "estadios de Eaton"10. En el examen físico, cabe mencionar que un resultado positivo en la "prueba del crujido" (sobrecarga y rotación axial del pulgar) es altamente sugestivo de la enfermedad (especificidad $80 \%-93 \%$ ), pero un resultado negativo no la descarta (sensibilidad $42 \%-53 \%)^{11}$. Hay una escasa correlación entre los síntomas y el grado de lesión radiológica; la sintomatología más severa puede acompañar a los cambios estructurales leves de la articulación y la enfermedad más avanzada podría hallarse asintomática. Esta discrepancia pone de relieve la necesidad de una observación "calma y racional" al momento de indicar el tratamiento, en lugar de una opción quirúrgica precoz.

El diagnóstico diferencial debe incluir otras causas de "dolor del lado radial" en la muñeca. La presentación de esta condición puede imitar la de un ganglión, ruptura tendinosa, fractura o inestabilidad del carpo, síndrome del túnel carpiano (puede coexistir con la rizartrosis), tenosinovitis de De Quervain, tenosinovitis estenosante del pulgar, ligamento colateral cubital desgarrado y la tendinitis del flexor radial del carpo ${ }^{12}$. Deberá tenerse en cuenta estas posibilidades diagnósticas frente al hallazgo de deformidad de la parte posterior de la muñeca, movilidad del carpo limitada o dolorosa, tumefacción o hematoma, prueba de Finkelstein positiva, bloqueo durante la flexión del pulgar, laxitud ligamentaria extrema y la falta de tendones flexores o extensores palpables al momento de evaluar la amplitud de movimiento.

Todos los pacientes que presentan esta afección, independientemente de la severidad de la misma, deben

\section{Correspondencia}

E-mail: rillo.oscar@gmail.com 
tener un período de tratamiento conservador. La mayoría puede beneficiarse con medidas no farmacológicas y farmacológicas. Opciones iniciales para el alivio del dolor incluyen el reposo, modificar la forma de realización de algunas actividades y los antiinflamatorios no esteroideos. Los ejercicios terapéuticos (fortalecer músculos tenares), la fisioterapia y la terapia ocupacional tienen un lugar importante en el tratamiento ${ }^{13}$.

El uso de ortesis reduce el dolor sin efecto sobre la función, fuerza o destreza ${ }^{14,15}$. Su función principal es estabilizar la base del primer metacarpiano, tratando de evitar la progresión de la aducción como la subluxación de la base. Este tipo de inmovilización disminuye el dolor y el paciente puede realizar la mayor parte de sus actividades de la vida diaria. Tienen que tener $30^{\circ}$ de abducción y mantener la interfalángica del primer dedo libre (férula corta). Su empleo es continuo durante 3 ó 4 semanas, y puede combinarse con medicamentos antiinflamatorios no esteroideos. Si hay mejoría después de este tiempo, los pacientes podrían utilizarla durante el día y gradualmente dejar de depender de ella en el transcurso de 1 mes. En esos casos, es aconsejable el empleo intermitente cuando haya síntomas o se realicen tareas que demanden carga articular.

En la primera etapa de la enfermedad, las inyecciones intraarticulares de corticoesteroides o ácido hialurónico pueden ser de utilidad. Ha sido mencionado que las infiltraciones con corticoesteroides, seguido por el empleo de férulas durante 3 semanas, pueden proporcionar alivio del dolor a largo plazo ( $>20$ meses $)^{4,12,16}$.

Si con el uso de la férula no hay mejoría de los síntomas después de 2 meses, deberán discutirse otras opciones terapéuticas ${ }^{13,17,18}$.

Ante la falla del tratamiento inicial, la resolución quirúrgica estará indicada para la enfermedad grave, definida por imágenes radiográficas y el dolor que persiste a pesar del tratamiento conservador ${ }^{12}$. La articulación carpometacarpiana del pulgar es el sitio más común en la mano para pensar en una eventual resolución quirúrgica ${ }^{4}$.

Aunque muchos pacientes informan de un alto grado de alivio postquirúrgico, es esperable que la fuerza en el pulgar disminuya respecto al valor de la misma en el preoperatorio ${ }^{19}$. La función es recobrada principalmente a expensas de una movilización libre de dolor.

Una amplia variedad de opciones quirúrgicas están disponibles y cuyo objetivo, indistintamente de la técnica a emplear será disminuir el dolor, mejorar la fuerza y por lo tanto restaurar la función de la mano.

Relacionado con el tratamiento conservador de la rizartrosis, en este número de la Revista Argentina de Reumatología aparece un interesante estudio sobre los efectos de la aplicación de taping (vendaje estabilizador del pulgar) en esta patología. De Cillis A. y cols. nos presentan los resultados de este novedoso método terapéutico, al compararlo con el empleo de una férula corta convencional. Además todos los pacientes podían recibir antiinflamatorios no esteroideos, drogas modificadoras de la enfermedad, comenzaron un programa de ejercicios específicos para el pulgar y fueron instruidos en principios de protección articular. Si bien al mes ambos grupos mejoraron en forma significativa el dolor y la capacidad funcional, la rigidez solo mejoró significativamente en aquellos pacientes que utilizaron el "taping". En esta muy buena propuesta de investigación, los autores mencionan que no existen hasta la actualidad publicaciones anteriores con esta pauta de tratamiento en la rizartrosis del pulgar y destacan que, además del efecto adicional sobre la disminución de la rigidez, el "grupo taping" tuvo una mayor adherencia al empleo del vendaje y no presentó eventos adversos. Por lo mencionado, los resultados sobre la utilización del taping en esta patología tan prevalente son alentadores. Si bien deberá corroborarse en un mayor número de pacientes, este método accesible y económico constituye una modalidad terapéutica aconsejable y a considerar en el tratamiento de la OA de la articulación trapeciometacarpiana.

\section{Bibliografía}

1. Dahaghin S, Bierma-Zeinstra SMA, Ginai AZ, Pols HAP, Hazes JMW, Koes BW. Prevalence and pattern of radiographic hand osteoarthritis and association with pain and disability (the Rotterdam study). Ann Rheum Dis. 2005;64(5):682-687.

2. Sonne-Holm S, Jacobsen S. Osteoarthritis of the first carpometacarpal joint: a study of radiology and clinical epidemiology. Results from the Copenhagen Osteoarthritis Study. Osteoarthritis Cartilage 2006;14(5):496- 500.

3. Gillis J, Calder K, Williams J. Review of thumb carpometacarpal arthritis classification, treatment and outcomes. Can J Plast Surg. 2011;19(4):134-138.

4. Batra S, Kanvinde R. Osteoarthritis of the thumb trapeziometacarpal joint. Orthopaedics and Trauma 2007; 21:135-44. 
5. Armstrong AL, Hunter JB, Davis TRC. The prevalence of degenerative arthritis of the base of the thumb in post-menopausal women. J Hand Surg. [Br] 1994;19:340-1.

6. Xu L, Strauch RJ, Atheshian GA, et al. Topography of the osteoarthritic thumb carpometacarpal joint and its variations with regard to gender age and osteoarthritic stage. J Hand Surg. [Am] 1998;23:454-64.

7. Dias R, Chandrasenan J, Rajaratnam V, Burke FD. Basal thumb arthritis. Postgrad Med J. 2007;83:4043.

8. Kellgren JH, Lawrence JS. Radiographic assessment of osteoarthritis. Ann Rheum Dis.1957;16:494-502.

9. Kwok WY, et al. The prevalence of erosive osteoarthritis in carpometacarpal joints and its clinical burden in symptomatic communitydwelling adults. Osteoarthritis Cartilage 2014 Jun;22(6):756-63.

10. Eaton RG, Glickel SZ, Littler JW. Trapeziometacarpal osteoarthritis: Stating as a rationale for treatment. Hand Clin. 1987;3(4):455-71.

11. Merritt MM, Roddey TS, Costello C, et al. Diagnostic value of clinical grind test for carpo meta-carpal osteoarthritis of the thumb. J Hand Ther. 2010; 23(3):261-7; quiz 268.

12. Cook GS, Lalonde DH. MOC-PSSM CME article: Management of thumb carpometacarpal joint arthritis. Plast Reconstr Surg. 2008;121:1-9.

13. Pomerance JF. Painful basal joint arthritis of the thumb. Part II: treatment. Am J Orthop. 1995;24:466-72.

14. Spaans A J, et al. Conservative Treatment of Thumb Base Osteoarthritis: A Systematic Review. J Hand Surg Am. 2015;40(1):16-2.

15. Marks E, Toby EB. Commentary to "Conservative Treatment of Thumb Base Osteoarthritis: A Systematic Review". J Hand Surg Am. 2015 Jan;40(1):22.

16. Day CS, Gelberman R, Patel AA, et al. Basal joint osteoarthritis of the thumb: a prospective trial of steroid injection and splinting. J Hand Surg Am. 2004; 29:247-51.
17. Barron OA, Glickel SZ, Eaton RG. Basal joint arthritis of the thumb. J Am Acad Orthop Surg. 2000;8:314-23.

18. Swigart CR, Eaton RG, Glickel SZ, et al. Splinting in the treatment of arthritis of the first carpometacarpal joint. J Hand Surg. 1999;24:86-91.

19. García-Mas R, Sole Molins X. Partial trapeziectomy with ligament reconstruction - tendon interposition in thumb carpometacarpal osteoarthritis. A study of 112 cases. Chir Main. 2009;28:230-8. 